\title{
Novelties Filtration Theory of Liquid Chromatography-Mass Spectrometry in Volume Nanotube of Cotton Filament of Layers Woven Fabrics
}

\author{
ElSayed A. ElNashar ${ }^{(1)}$ \\ Department of Home Economic, Faculty of Specific Education, Kaferelsheikh University, Kaferelsheikh City, Egypt \\ Email: Smartex@kfs.edu.eg
}

How to cite this paper: ElNashar, E.A. (2021) Novelties Filtration Theory of Liquid Chromatography-Mass Spectrometry in Volume Nanotube of Cotton Filament of Layers Woven Fabrics. Journal of Textile Science and Technology, 7, 14-21. https://doi.org/10.4236/jtst.2021.71002

Received: December 3, 2020

Accepted: January 23, 2021

Published: January 26, 2021

Copyright $\odot 2021$ by author(s) and Scientific Research Publishing Inc. This work is licensed under the Creative Commons Attribution-NonCommercial International License (CC BY-NC 4.0). http://creativecommons.org/licenses/by-nc/4.0/ cC) (i) (8) Open Access

\begin{abstract}
Objectives of the research to present a modern theory of water purification for multiple purposes entitled "a novelties filtration theory of liquid chromatography-mass spectrometry" is an exceedingly sensitive and specific analytical technique in volume layers woven fabrics that can precisely determine the identities and quantities of compounds within volume Nanotube of cotton filament of layers woven fabrics. The problems are that the filters in the local and international markets have increased complications in configuration, installation and cost without reaching the efficiency that humanity hopes. Throw materials and methods the chromatography-mass spectrometry in layers woven fabrics, and throw the nanotube of cotton filament for purification of water dyes and smells. Industry, in which mass spectrometry is a convenient, versatile method for characterization and identification of process throw the Nanotube of cotton filament for purification of water dyes and smells. Results came up with a theme "innovations in textiles", and also, for characterization of fibers and contaminants of the fabrics. Additive manufacturing in layers woven fabrics, are the processes used to synthesize a volume object under computer control with successive material layers that have been used and highlighted. The conclusions has included chromatography-mass spectrometry drop, physico-chemical, biological, combined physical-biological and chemical-biological treatment processes recently being developed to meet Jet-filtration, the strict discharging limits set by ASTM standards. Some important aspects of both qualitative and quantitative data analysis have been described and the power of using mass profiles to enhance selectivity and sensitivity has been demonstrated.
\end{abstract}




\section{Keywords}

Filtration Theory, Liquid Chromatography-Mass, Spectrometry, Layers, Woven Fabrics

\section{Introduction}

Euro Microfluidics 2020 are brought together by microfluidics scientists and nano-system people to showcase the newest developments and discuss future directions in microfluidic technologies and their applications in complex systems, are broadly defined. The topics will be wide-ranging, including chemical synthesis, separations, advanced manufacturing approaches, energy and the environment, multiphase and colloidal systems, systems biology, synthetic biology, biophysics, organs-on-a-chip, and precision medicine. Some important microfluidics applications have been plot so as to give a thought on how this new science can both assist and lift look into in fields like science and prescription. In any case, there is a ton of space for enhancements so as to spread more microfluidics applications past research simply [1]. Novel functionalities can be delivered to textiles by integrating smart polymers into them. [2], and Analytical Mathematical Modelling of Microarrays Volume Porosity [3] [4] [5], which throw a laser spectroscopy in-permeability characterization of engineering textiles [6] [7]. As the filaments as filtration of textiles industry play a critical role in our daily activities, it contributes to fulfilling the basic living fabrics requirements of human life. The filaments as filtration textile industry have developed rapidly in developing countries in recent years, which has led to increasing concerns filaments of textile as filtration wastewater pollution. Jet-Airbags in Monitoring System [8], as Filament of Textiles as Jet-filtration wastewater and agricultural wastewater as well as drainage for fish farms generally contains various chemicals such as dyes (i.e., azo dyes, triphenylmethanes dyes anthraquinone dyes, nitroseds dyes, xanthenes dyes, phthalocyanines dyes, polymethine dyes, and indigoids,) and inorganic compounds, metals and heavy metal. The next many researches addressed to Green Antimicrobial Jetfiltrations of Membrane Nanotechnology for Water/Wastewater for the Middle-East Region [9], and a Smart Emerging Technology for the high colour density [10].

High concentration of recalcitrant organics and $\mathrm{pH}$, high salinity and turbidity make filament of textiles wastewater be one of the most heavily contaminated waters to be treated or if left untreated, these filaments as Jet-filtration of water of textile dyes present serious concern to environmental and human health. We presented a comprehensive review of the various studyof textile wastewater treatment using Jet-filtration chromatography-mass photocatalytic oxidation throw filaments as Jet-filtration process. The abstract investigated and compared the efficiency of using chromatography-mass spectrometry process [11] through volume of porosity and metal and nonmetal doping and co-doping [12]. 
It has also discussed the efficacy of using modified Spectrometry photocatalyst for Filament textiles Layers Woven Fabrics [13], for wastewater treatment. The inventor concluded the major advantages and disadvantages using chromatography-mass spectrometry and strategies to enhance chromatography-mass spectrometry oxidation performance a macroporosity and air permeability in two-layer woven fabrics [14]. Desalination system uses wicks [15], with potentials of using natural leaf-based materials to treat dyes. The inventor introduced the characteristics of leaf-based materials, experiment study for dye removal, and their potential application in pilot and full-scale settings. The inventor also investigated the kinetics of dye adsorption using this natural material, of various dyes and pigments (indigo, dispersed, reactive, sulfur, and vats. Used in Filament as Jet-filtration of textile manufacturing processes and discussed their potential impact on the environments such as agricultural wastewater as well as drainage for fish farms. The inventor indicated that the majority of the dyes belong to azo groups which typically features high stability and poses carcinogenic effects on the environmental ecosystems.

\subsection{Theory}

Novelties Jet-filtration theory of liquid chromatography-mass spectrometry in volume nanotube of cotton filament of layers woven fabrics, with a view: Attracting, withdrawing or suctioning liquids to be removed, from plankton or colors, through a media with information on the structure and properties, to known degrees of purity, at a certain time and quantity.

\subsection{Problems}

The problems are that the filters in the local and international markets have increased complications in configuration, installation and cost without reaching the efficiency that humanity hopes.

The divergence of the fields of theoretical studies for applied cases and an attempt to relate them to the new filtering theory of liquid chromatography-mass spectrometry in nanotubes of cotton yarn from layers of woven fabrics.

\subsection{The Objectives}

1) To conduct an experimental investigation Novelties Filtration Theory of the new process of Nanotube of Cotton Filament.

2) To establish a new theory of liquid chromatography-mass spectrometry granular media of Jet-filtration layers woven fabrics simultaneous contact flocculation and filtration.

3) To establish mathematical formulas describing the process pressure theory of Jet-filtration liquid chromatography-mass spectrometry drop and the root mean square of velocity gradient in the different media of bed Jet-filtration.

4) Is to shine a light on the newest textiles' treatment Jet-filtration technologies. The abstract has included chromatography-mass spectrometry drop, phy- 
sico-chemical, biological, combined physical-biological and chemical-biological treatment processes recently being developed to meet Jet-filtration the strict discharging limits set by ASTM standards.

\section{Materials and Methods}

Chromatography-Mass Spectrometry degradation as Jet-filtration investigated the Chromatography degradation potential of methylene blue (MB) dye in synthetic textile's wastewater. The inventor has utilized as filtration composite to measure treatment performance. The obtained highest degradation of $\mathrm{MB}$ is $95 \%$ and was achieved at as Jet-filtration dose ratio. This optimum degradation rate was achieved when $\mathrm{pH}$ is $9.2, \mathrm{MB}$ concentration of $8 \mathrm{mg} / \mathrm{L}$ and composite does of $0.7 \mathrm{~g} / \mathrm{L}$ under 2 hours of chromatography-mass spectrometry radiation. The inventor has summarized the pros and cons of this treatment Jet-filtration technology and suggested further biological treatment should be used to remove the MB by-product produced during degradation as Jet-filtration oxidized Reactive Black 5 textile liquids of dye using plasmonic photocatalyst. The inventor has designed a Jet-filtration composite plasmonic photocatalyst using as filtration as the semiconductor and silver nanoparticles as the plasmonic base. The study of Jet-filtration has obtained a $75 \%$ higher reaction rate constant compared to using as Jet-filtration alone as Jet-filtration various using advanced oxidation process to treatment textiles wastewater. The inventor compared and analyzed the performance of ozone-based process, photochemical processes, Fenton, photo-Fenton processes, and electrochemical based processes. They suggested that advanced oxidation processes are the most promising treatment technologies in as filtration textiles wastewater remediation.

\section{Results and Discussions}

This Jet-filtration explored the treatment performance of using different coagulants in tex-Tiles as filtration water/wastewater remediation. Throw invention in Figure 1. ElNashar's filter. According Novelties Filtration Theory of Liquid Chromatog-raphy-Mass Spectrometry in Volume Nanotube of Cotton Filament of Layers Woven Fabrics, and The study of Jet-filtration have an advanced component of membrane that have focused on the following operation parameters: color, turbidity, and absorbance. The inventor has picked two types of coagulants: organic coagulant Moringa oleifera Lam seeds and in-organic coagulant aluminum sulfate. As Jet-filtration that the organic coagulant has yielded higher removal efficiency (COD of $96 \%$ and color of $97 \%$ for OP-HER dyes) compared to aluminum sulfate This Jet-filtration also found that $\mathrm{pH}$ is a key factor in affecting coagulation Efficiency.

\subsection{Membrane}

Membrane of The filaments as filtration of textiles industry removal efficiency of rose Bengal, yellow dyes, and sodium dodecyl sulfate surfactant present in synthetic 


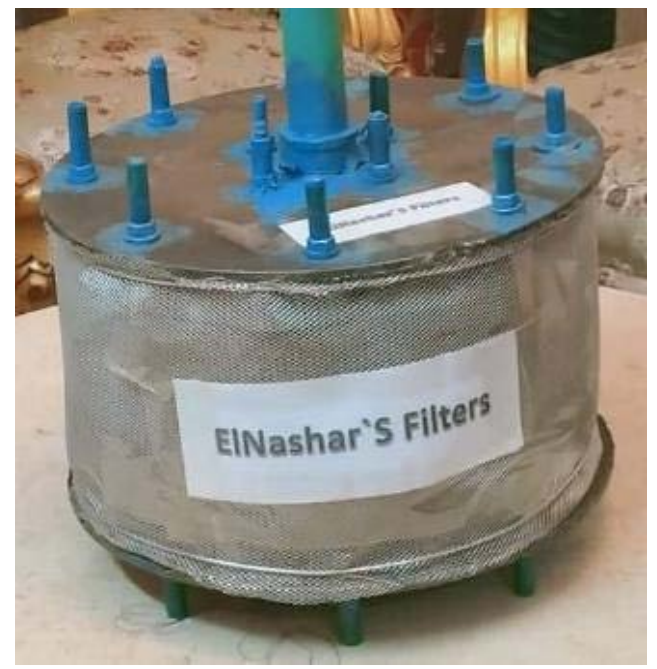

Figure 1. ElNashar's filter. According novelties filtration theory of liquid chromatography-mass spectrometry in volume nanotube of cotton filament of layers woven fabrics.

textiles wastewater using air gap chromatography-mass spectrometry membrane distillation (CSMD) filtration process. This study has used salt and color removal as performance indicator and found $98 \%$ of salt and color removal after $15 \mathrm{~h}$ of testing. The inventor also reported that the filtration technology removed all dyes surfactants and salts completely with this one-step process. This is considered as one of the most highly promising technology for wastewater application with reduced flux decline and higher thermal efficiency. The inventor has used a sophisticated membrane chromatography-mass spectrometry reactor (MCSR) system with zinc oxide capped with polyethylene glycol (ZnO-PEG) nanoparticles and polypiperazine-amide tight Nanotube of Cotton Filament membrane (NCFM). The abstract has concluded the optimum operating conditions of system were obtained at $\mathrm{pH}$ of $11,0.10 \mathrm{~g} / \mathrm{L}$ of $\mathrm{ZnO}-\mathrm{PEG}$ nanoparticles, and $89 \%$ dilution of industrial textile wastewater. They have also characterized treatment performance and explored removal mechanism using Filament emission nanotube chromatography-mass spectrometry (FENCMS) and atomic force microscopy analyses to further confirm the effectiveness of combined ZnO-PEG nanoparticles and the membrane system [16]. The combinations of Jet-filtration (JF) and nanofiltration (NF) membranes are as a novel treatment method of textiles wastewater. The achieved color, and conductivity removal were close to 99.0\% in treated wastewater effluent and considered as the most promising technology to achieve the required water quality for water recycling and reusing purposes [17].

Particle Beam Ionization and The developed particle beam interface to separate the solvent from solute with minimum loss of solutes.

\subsection{Color Removal of Water}

This paper aim to color Stripping of water, Discoloration from the water or discussed various technique to color removal of water physico-chemical (i.e. Na- 
notube of Cotton Filament, adsorption, advanced oxidation process such as chromatography-mass spectrometry and coagulation-flocculation), biological and combined processes. The varying treatment efficiencies related to color Stripping of water, dye degradation, and color removal, which have been observed to be either completely or partially achieved in the present color stripping of water. Thus, color stripping of water is needed to focus on parameter optimization and the utilization of combined textiles Jet-filtration treatment processes. Mass Analyzer After ionization the water physico-chemical are transferred into mass Analyzer where the separation of ions are done according to their mass to charge $(\mathrm{m} / \mathrm{z})$ ratio Nanotube of Cotton Filament. Generally mass Analyzer used is on its speed, time, rate and its reaction. It is strongly recommended that Jet-filtration investigate the feasibility of alternate and optimized treatment systems in industrial settings, with a particular focus on respecting the integrity and efficiency of Jet-filtration treatment processes. The liquid chromatography separates mixture of components which are in liquid form throw Nanotube of Cotton Filament, usually contains plankton and water. This liquid containing mixture of components is transferred into the ion source of mass spectrometer. As oxidation process Membrane source is under high vacuum. Due to the difference in the pressure it is difficult to mass to vaporize the liquid drops without losing mixture of components of Membrane the filaments as filtration of textiles industry. Hence interfaces are used to resolve this problem. The different types of Membrane the filaments as filtration of textiles industry interfaces commonly used in mass spectrometer are described.

\section{Challenge and Opportunities}

The divergence of the fields of theoretical studies for applied cases and an attempt to relate them to the new filtering theory of liquid chromatography-mass spectrometry in nanotubes of cotton yarn from layers of woven fabrics.

\section{Conclusion}

The novelties filtration theory of liquid chromatography-mass spectrometry in volume Nanotube of cotton filament of layers woven fabrics is a hyphenated technique used in combination with Mass spectrometry. It is widely used in pharmaceutical, chemical, food and agrochemical industries. Novelties Jet-filtration theory is used for qualitative and quantitative determination of drug substances and biological samples. Also, it is commonly used in drug research and quality control of in volume Nanotube of cotton filament of layers woven fabrics, with a view: attracting, withdrawing or suctioning liquids to be removed, from plankton or colors, through a media with information on the structure and properties, to known degrees of purity, at a certain time and quantity.

\section{Conflicts of Interest}

The author declares no conflicts of interest regarding the publication of this paper. 


\section{References}

[1] ElNashar, E.A. (2019) Market Analysis Report on Microfluidics \& Nanofluidics. Journal of Chemistry and Applied Chemical Engineering, 3, 3-5.

https://www.scitechnol.com/peer-review/market-analysis-report-onmicrofluidics-n anofluidics-AQtE.php?article_id=10377

[2] ElNashar, E.A. (2020) Smart Material and Functional Polymers into Applications of Textiles and Apparel: Global. Biopolymers \& Polymer Chemistry Congress, Las Vegas, 12-13 November 2019, 51.

https://phronesisonline.com/polymer-chemistry-congress/index.php

[3] ElNashar, E.A. (2020) Analytical Mathematical Modelling of Microarrays Volume Porosity in Mesh Knitting Material for Fisheries Technology. The 8th Annual Conference of AnalytiX-2020, Kyoto, 5-7 March 2020.

[4] ElNashar, E.A. (2017) Mathematical Modelling of Volume Porosity in Mesh Knitting for Fisheries Technology. 12 th World Congress on Aquaculture \& Fisheries, Hong Kong, 13-14 August 2018, 1.

https://www.researchgate.net/publication/318815940_MATHEMATICAL_MODEL LING_OF_VOLUME_POROSITY_IN_MESH_KNITTING_FOR_FISHERIES_TEC HNOLOGY

[5] ElNashar, E.A. (2017) Antimicrobial of Volume Porosity in Nonwoven Membrane Technology for Water/Wastewater-Filtrations. EMS Engineering Science Journal, 1, 005. https://emspublishers.org/article.php?articleId=1021

[6] ElNashar, E.A. (2019) Laser Spectroscopy In-Permeability Characterization of Engineering Textiles. WCMSE-2019. 2nd World Congress on Materials Science and Engineering, Las Vegas, 12-14 November 2019, 23.

[7] ElNashar, E.A. and Dmitry, P. (2019) Theoretical Analyses of Laser-Jet Technology for Cutting 3d Velvets Fabrics on Weaving Machine. World Congress on Lasers, Optics and Photonics, Theme: Advancements of Lasers, Optics and Photonics in Modern World, Barcelona, 23-25 September 2019, 62. http://www.phronesisonline.com/optics-conference/

[8] ElNashar, E.A. (2019) Design Analysis of Functional Textilesfor Smart Airbags by Nanotechnology Inautomotive Industry. 4-19.

https://scientificfederation.com/physics-2019/committee.php

[9] ElNashar, E.A. (2018) Green Antimicrobial Jetfiltrations of Membrane Nanotechnology for Water/Wastewater for the Middle-East Region. Resource-Saving Technologies of Light, Textile \& Food Industry International Scientific-Practical Internet-Conference of Young Scientists \& Students, Ukraine, 15-16 November 2018, 106.

[10] ElNashar, E.A. (2018) Smart Emerging Technology to Development Curtains and Upholstery for Theaters and Hospitality. Annual Congress on Emerging Materials and Nanotechnology, Bangkok, 6-7 September 2018, 1.

[11] Erials and Nanotechnology. 6-7 September 2018, Bangkok. http://www.alliedacademies.org/conference-abstracts-files/biomedicalresearch-C4-0 11-008.pdf

[12] ElNashar, E.A. (2018) Volume of Liquid Chromatography-Mass Spectrometry in Terry Woven Fabrics. Expand and Explore the Novel Enhancement in Liquid Chromatography_Mass Spectrometry, Hong Kong, 21-22 September 2018. https://lcms.massspectra.com/organizing-committee.php

[13] ElNashar, E.A. and Albu, A. (2018) Volume Wicking and Wetting in Terry Woven 
Fabrics. Latest Trends in Textile and Fashion Designing, 2, 125-129.

http://www.lupinepublishers.com/lttfd/pdf/LTTFD.MS.ID.000127.pdf https://doi.org/10.32474/LTTFD.2018.02.000127

[14] ElNashar, E.A. (2005) Volume Porosity and Permeability in Multi-Layer Woven Fabrics. Autex Research Journal, Poland, December 2005, 207-218.

http://www.autexrj.com/articles/35/189

[15] Dubrovski, P.D. and ElNashar, E.A. (2003) Macroporosity and Air Permeability in Two-Layer Woven Fabrics-[P-COM1]. World Textile Conference 4th Autex Conference Roubaix, France, 22-24 June 2004, 501-502.

[16] Omara, Z.M, Eltawil, M.A. and ElNashar, E.A. (2013) A New Hybrid Desalination System Using Wicks/Solar Still and Evacuatedsolar Water Heater. Desalination, 325, 56-64. https://www.journals.elsevier.com/desalination https://doi.org/10.1016/j.desal.2013.06.024

[17] ElNashar, E.A. (2018) Jetfiltrations of Membrane Technology to Water/Wastewater for the Middle-East Region. 2nd International Conference on Membrane Science and Technology, London, 13-14 September 2018, 172-180.

https://membranescience.conferenceseries.com/ 